\title{
La Religión y la construcción del Capital Social
}

\author{
Yonathan Mario Gonzáles Ttito \\ ygonzalestt@unsa.edu.pe \\ María Jesús Rodríguez Checca \\ mj_firstdate22@hotmail.com \\ Humberto Denny Altuna Sotomayor \\ haltuna@unsa.edu.pe \\ Universidad Nacional de San Agustín de Arequipa
}

\section{RESUMEN}

El objetivo de la ponencia es Identificar el papel que desempeñan las religiones Católica y Adventista en la construcción del capital social en los jóvenes y adolescentes que participan activamente en los grupos promovidos por estas iglesias, El tipo de estudio es Básico, con enfoque cuantitativo mixto, El Diseño es Descriptivo comparativo. Los elementos en los que se sostiene el capital social se construye de modo diferenciado entre los creyentes de determinadas religiones. Ello debido a las diferentes doctrinas y creencias que se imparten al interior de las iglesias. Así, la confianza, la solidaridad, la reciprocidad y la cooperación se expresan en mayor o menor nivel de intensidad y de forma diferente. Los resultados obtenidos en este estudio nos llevan a concluir que al interior de la las iglesias el capital social es más activo entre los creyentes de una misma religión y que el capital social se proyecta de forma menos intensa hacia el exterior de las iglesias, en otros términos, las actitudes de confianza y las relaciones de solidaridad, reciprocidad y cooperación son más intensas entre los creyentes de una misma religión que con personas externas a sus grupos de acción.

Palabras clave: Religión; capital social; solidaridad; confianza 


\title{
Religion and the construction of Social Capital
}

\begin{abstract}
:
The objective of the presentation is to identify the role that the Catholic and Adventist religions play in the construction of social capital in the youth and adolescents who actively participate in the groups promoted by these churches. The type of study is Basic, with a mixed quantitative approach, The Design is descriptive comparative. The elements on which social capital is sustained is built differently among the believers of certain religions. This is due to the different doctrines and beliefs that are taught within the churches. Thus, trust, solidarity, reciprocity and cooperation are expressed to a greater or lesser level of intensity and in a different way. The results obtained in this study lead us to conclude that inside the churches, social capital is more active among believers of the same religion and that social capital is projected less intensely outside the churches, in others terms, attitudes of trust and relationships of solidarity, reciprocity and cooperation are more intense among believers of the same religion than with people outside their action groups.
\end{abstract}

Keywords: Religion, social capital, solidarity and trust

Artículo recibido: 06. julio. 2020

Aceptado para publicación: 09. setiembre. 2020

Correspondencia: ygonzalestt@unsa.edu.pe

Conflictos de Interés: Ninguna que declarar 


\section{INTRODUCCIÓN}

Max Weber, Emilio Durkheim y Carlos Marx, los más grandes ilustres de la sociología moderna, plantean aspectos interesantes sobre la religión desde diversos enfoques, los cuales son necesarios retomarlos en la actualidad. Los tres conciben que la religión está intensamente vinculada a la vida social. Intentamos unir estos planteamientos al capital social, que por cierto muchos de sus elementos también han sido considerados por estos notables pensadores. Hemos retomado algunas ideas formuladas por los autores en mención y tratado de aplicarlas a la realidad con la intención de buscar nuevos caminos que nos puedan ayudar a superar la pobreza de países como el nuestro. De este modo surge La Religión en la Generación del Capital Social. El título hace alusión al papel que desempeña la religión en la construcción del capital social. Entendemos que, al haber diferentes religiones, los elementos en los que se sostiene el capital social se construye de modo diferenciado entre los creyentes de determinadas religiones.

Ello debido a las diferentes doctrinas y creencias que se imparten al interior de las iglesias. Así, la confianza, la solidaridad, la reciprocidad y la cooperación se expresan en mayor o menor nivel de intensidad y de forma diferente. Este estudio es el resultado de un año académico de investigación, tanto en el campo de lo teórico como en la práctica misma. Con el cual esperamos contribuir con elementos que sirvan de base para posteriores investigaciones y proyectos de desarrollo que prioricen aspectos culturales y sociales, lo cual no significa que este estudio también no pueda ser sustento de otros enfoques. El presente trabajo establece comparaciones entre las iglesias: Católica y Adventista del distrito de Alto Selva Alegre, donde analizamos la proyección del capital social de los creyentes de ambas iglesias hacia el exterior de las mismas.

\section{MATERIALES Y MÉTODOS}

\section{Planteamiento del problema}

La presencia de diversas religiones en el Perú ha sido cada vez mayor no sólo en número, también en su incursión dentro de una amplia gama de cuestiones sociales; generando opinión pública en temas como la legalidad del aborto, la equidad de género, la participación en los comicios electorales, entre otros. Detrás de la imagen que puedan proyectar estas religiones se entrelazan distintas configuraciones de relaciones sociales entre sus miembros. La sociabilidad no es un elemento del que estén desprovistas; por el 
contrario, el sentido que le atribuyan a esta influye en la direccionalidad de sus comportamientos; pero siempre enmarcados dentro de un conjunto de creencias y prácticas que les provee significado. Proporcionan proyectos de conducta social basados en un orden divino, sobrenatural o trascendental.

\section{Metodología: universo, unidad de análisis}

La presente investigación se realiza en el distrito de Alto Selva Alegre. Para el logro de nuestros objetivos consideramos lo siguiente:

Primero: el universo está constituido por el total de los jóvenes creyentes activos que se encuentran entre los 14 y 30 años de edad, pertenecientes a las organizaciones sociales promovidas tanto por la iglesia católica como por la adventista en el distrito de Alto Selva Alegre.

Segundo: Constituyen nuestras unidades de análisis; a) el sistema de doctrinas y creencias de las religiones Católica y Adventista, y b) los creyentes de ambos sexos que participan activamente en los grupos religiosos y cuyas edades fluctúan entre los 14 y 30 años.

Tercero: utilizamos como técnicas de recolección de datos el análisis documental para extraer del sistema de creencias y doctrinas religiosas los elementos que refuerzan o limitan el capital social (objetivo 1); así mismo utilizamos la encuesta para identificar las características socioeconómicas de los creyentes activos, como también para identificar las características del capital social entre los creyentes de la misma iglesia y de estos hacia el exterior de su iglesia (objetivos 2, 3 y 4).

Cuarto: El tamaño de la muestra se determina a partir del número total de creyentes activos existentes en el total de grupos religiosos tanta católicos como adventistas en las principales iglesias del distrito de Alto Selva Alegre. Por consiguiente, se obtienen dos muestras: la primera constituida por 103 creyentes de 140 pertenecientes a la religión adventista. La segunda, conformada por 134 creyentes de 210 pertenecientes a la religión católica. Ambas, se han obtenido según fórmula ${ }^{1}$, con el máximo de dispersión, y tienen un nivel de confianza del 95\% y un error de estimación de 0.05 (5\%). 
Para realizar un abordaje apropiado y tomando en cuenta a la sociología, es que abordamos el tema a partir de lo que conocemos como la sociología de la religión que viene a ser es: el estudio de los comportamientos, estructuras sociales, evolución y de los roles de las religiones en las sociedades humanas. Intenta explicar la influencia que la religión tiene en el comportamiento colectivo del hombre y vice-versa, es decir, las interacciones recíprocas entre religión y sociedad.

\section{Marco teórico sobre la religión}

\subsection{Enfoques sociológicos sobre la religión}

\section{Carlos Marx: "la religión es el corazón de un mundo sin corazón"}

Marx (1818-1883) creía que lo más significativo de las sociedades industriales de su época era que éstas se dividían en dos clases sociales antagónicas. Por un lado, los capitalistas, propietarios de los medios de producción, y por el otro, el proletariado, trabajadores que producían los bienes económicos. Sostiene que los primeros incrementan cada vez más sus riquezas, mediante la explotación a los trabajadores, apropiándose de la plusvalía que estos generan. La religión en este contexto sirve como mecanismo de sujeción que las clases dominantes utilizan para contener a las grandes masas empobrecidas en el sistema económico-productivo vigente. Argumenta que la sociedad capitalista se mantiene unida mediante la destreza de los capitalistas para dominar a los trabajadores. La religión por su parte, cumple el imperativo de hacer creer a la gente que los ordenamientos sociales son justos, o en caso de no serlo, ineludibles. La opinión de Marx sobre la religión se basa en su creencia de que el hombre creó a Dios para atribuirle todas aquellas cualidades que no podía alcanzar, como recompensa a los sufrimientos que padecían los obreros explotados, recibirían una vida de felicidad después de la muerte. Marx reconoce que en periodos históricos anteriores la religión alcanzó algunos puntos importantes a favor de los grupos oprimidos y que estaba asociada con el progreso, pero en tiempos de la sociedad capitalista moderna se ha convertido en una fuerza conservadora. Sus críticas a las creencias religiosas no son como sostienen Donald Light (1991) y Gelles (1992) negativas en extremo, sino hasta cierto punto comprensibles. Muchos creen que Marx desprecia la religión, pero esto está lejos de la verdad. Desprecia la forma cómo es utilizada para justificar la desigualdad, pero entiende que la religión 
proporciona un espacio de tranquilidad frente a la dureza de la realidad. En la "Crítica a la filosofía del derecho de Hegel", escribe: "la religión es el alma de un mundo sin alma, y el corazón de una sociedad sin corazón”. En la introducción del mismo libro aparece la expresión "la religión es el opio del pueblo". Numerosos textos contienen esta cita, pero de estos son también numerosos los que reflejan una interpretación negativa. Sobre la base de esta interpretación, deducen que la religión debe ser eliminada. Marx no se declara en contra de la religión en sí, sino en contra de la forma como la utilizan las clases dominantes, al enseñar la aceptación de las condiciones de injusticia y la resignación a vivir en desigualdad. Esto genera la esperanza de alcanzar la felicidad después de la muerte. La crítica que Marx hace sobre la religión se deriva de la idea de que los grupos dominantes han inducido y reforzado la desigualdad y el poder a su favor. Sostiene que cuando las personas dejen la creencia de la aceptación de las desigualdades, comenzarán a demandar felicidad para sus vidas aquí en la tierra. Para alcanzar esta felicidad terrenal propone un horizonte político al cual alcanzar: el comunismo. Para llegar a él, plantea que los proletarios de todo el mundo han de unirse Marx (1848), cooperar entre ellos y trabajar juntos por un objetivo en común. Es así como Marx ofrece una nueva esperanza a millones de corazones humanos. El mensaje anunciador del paraíso terrenal, significa para cientos de miles de personas un nuevo rayo de luz y un nuevo sentido de la vida Schumpeter (1942).

\section{Emilio Durkheim: la religión como elemento de integración}

Otro de los pensadores que tiene inmensa influencia en distintas corrientes del pensamiento es el francés Emilio Durkheim (1858-1917). Al analizar el desarrollo de las sociedades industriales modernas, señala la forma como las fuerzas sociales intangibles hacen posible la integración de las personas. Durkheim atribuye especial énfasis a la cultura, a las ideas de la sociedad y los valores. Su análisis se basa en el modelo teórico funcionalista, y haciendo uso de este sostiene que la religión crea y mantiene comunidades morales. Ve a la religión como un elemento benéfico, debido a que promueve compromisos sociales entre las personas a partir de creencias intersubjetivamente valoradas y compartidas. Durkheim define a la religión como un conjunto de creencias y prácticas que pertenecen a cosas sagradas que unen a la gente dentro de una comunidad moral. La religión ocupa un lugar central en la vida de las 
personas. Tiene un carácter social. Este carácter se expresa en una comunidad regida por un orden moral. Esta perspectiva asume que la religión es el resultado de una estructura social relativamente estable, en donde los individuos siguen la creencia de que se hallan dominados por fuerzas sociales externas a ellos mismos, fuerzas sobre las cuales tienen un limitado control o posiblemente ninguno. Esta configuración social define fuertemente el comportamiento de las personas, aunque ellas inconscientemente las llevan implícitas y no se dan cuenta de que sus acciones están siendo normadas por una instancia superior, externa y muchas veces coercitiva. Aunque esta perspectiva haya sido fuertemente criticada por considerar la opinión de Durkheim sobre la religión un tanto exagerada, no deja en parte de tener razón. La comunidad moral, como la denomina Durkheim, la componen quienes comparten creencias y prácticas que los unen conjuntamente en una unidad social más amplia, a la que sirven con respeto y obediencia. En cierta forma, la religión construye comunidad mediante las relaciones establecidas entre los miembros aferrados a una creencia compartida.Pero la crítica desde la perspectiva de la acción a la visión funcional-estructuralista de Durkheim, hace énfasis al hecho de que la religión es también producto de las acciones y elecciones individuales. Más allá de entrar a esta discusión, interesa ver los aportes de Durkheim acerca de la religión.

Con pocas dudas - por no decir ninguna- reconoce que la sociedad se mantiene unida por vínculos sociales compartidos. En primer lugar, la religión tiende a promover la solidaridad social, estableciendo en parte normas que reducen los conflictos en la sociedad, e imponiendo sanciones a quienes las transgredan. Pero también al ofrecer formas de corregir los errores a quienes tengan conductas consideradas antisociales. En segundo lugar, la religión legitima el orden social al reafirmar las disposiciones sociales establecidas como correctas y deseables. La religión en gran parte, dentro del sistema teórico de Durkheim, hace posible que la sociedad se mantenga unida para impulsar vínculos a nivel social. La confianza mutua y la interdependencia generan un sentido de pertenencia. Esto permite que la sociedad se realice como una unidad mayor, más que como la suma de sus miembros individuales Light (1991).

La fuerza social que cohesiona a las personas, es un fenómeno que el autor denomina "solidaridad social". Esta solidaridad se expresa en opinión de Durkheim en dos formas básicas. Una conocida con el nombre de solidaridad mecánica que se basa en la 
participación común de creencias, valores y costumbres. Esta es practicada en las sociedades premodernas. En cambio la solidaridad orgánica se presenta en sociedades modernas, en donde la división del trabajo y la interdependencia son más complejas. Las conexiones sociales son bastante fuertes, debido a que las diferencias en habilidades y funciones hace que la gente se necesite una a otra para sobrevivir.

\section{Max Weber: la religión como agente para la generación de riqueza}

Weber (1864-1920), uno de los intelectuales más importantes de su tiempo, creía que la explicación a los fenómenos debe derivarse de la comprensión, de por qué las personas eligen opciones determinadas y no otras. Su argumentación de que los hechos sociales son el resultado acumulado de acciones individuales lo lleva a observar más allá del comportamiento objetivo. "La ética protestante y el espíritu del capitalismo" es una de sus obras más importantes. En ella Weber nos presenta su interrogante a partir de observaciones en países con poblaciones protestantes y católicos: ¿Que hace que los protestantes fomenten la empresa económica y que por el contrario los católicos la eviten? $\mathrm{Su}$ explicación se enfoca sobre las creencias subjetivas de los creyentes, sobre sus actividades, valores y motivaciones.

La iglesia católica enseñó que la salvación es el significado de la vida, a la que sólo se accede por medio de la participación en los sacramentos, la renuncia a los bienes materiales y viviendo en la pobreza. Durante siglos condena la búsqueda de la ganancia. En cambio la creencia calvinista de que la salvación está predeterminada desde el nacimiento y que no se podía hacer nada para cambiarlo, genera ansiedad en las personas al no saber si es o no una de las elegidas. Pero resuelven este dilema considerando al logro material como una señal divina. Revalorizan la importancia del valor del trabajo y la austeridad. Renuncian a la satisfacción inmoderada de los deseos, la búsqueda del lujo y los placeres carnales. Al mismo tiempo, no aceptan la creencia de la salvación mediante la renuncia a las posesiones materiales y a vivir en situación de pobreza. Las ideas protestantes se sustentan en las actitudes favorables hacia el trabajo y hacia la inversión, deviniendo en éxito material. Y que tal éxito es la respuesta al favor de Dios para la vida eterna. Así nace la ética protestante. 


\subsection{El capital social}

Sobre la base de las características señaladas por Aliaga (2003) al capital social, podemos identificar seis atributos de este. Primero, al igual que cualquier capital, representa una inversión con expectativa de retorno. Segundo, esta inversión requiere de mantenimiento, por lo que es necesaria la renovación de compromisos. Tercero, el capital social, no se ubica en uno mismo sino en la relación con los demás. Cuarto, no tiene una tasa de depreciación predecible mientras se mantengan los compromisos, puesto que no se desgasta con el uso y sus beneficios, son difíciles de determinar en el tiempo. Quinto, como cualquier otro capital es apropiable en el sentido de que puede ser utilizado para diferentes propósitos. Finalmente, es convertible porque puede traducirse en el incremento de otros capitales.

En el marco de esta investigación, asumimos que el capital social depende intensamente de los patrones culturales que las personas consideran importante en el curso de sus vidas. Sin embargo, no negamos que el capital social tenga otras causas; al contrario, tenemos presente que también depende, y con gran incidencia, del acceso a otras formas de capital y del capital humano; a su vez que el mismo capital social genera más capital social, pero no en el sentido de una causación circular sino en forma de espiral ascendente. Como venimos señalando, la religión genera capital social. Las razones que nos llevan a tal afirmación, las resumimos en dos puntos: a) la religión provee de determinados contenidos doctrinales a las personas que los condicionan a tener determinados comportamientos, y b) son estas doctrinas y creencias las que potencializan las relaciones sociales de los creyentes, traduciéndose en algún nivel de confianza, solidaridad, reciprocidad y cooperación. Pero hablar de religión nos conduce a tener en cuenta que existe una variedad de religiones. Precisamente esa diversidad es la que potencializa el capital social de sus seguidores en niveles diferenciados.

Presentamos a continuación algunas definiciones y conceptos que se han elaborado para entender el significado del capital social.

Ocampo señala que el "capital social es el conjunto de relaciones sociales caracterizada por actitudes de confianza y comportamientos de cooperación y reciprocidad. Se trata, pues, de un recurso de las personas, los grupos y las colectividades en sus relaciones 
sociales, con énfasis en las redes de asociatividad de las personas y los grupos" Ocampo (2003).

Por su parte Fukuyama (1996), sostiene que el capital social se basa en raíces culturales. “...es perfectamente posible que tradiciones culturales que no se basan en un razonamiento material, prácticas como hábito y con el fin de alcanzar la gloria en otro mundo, pueden, sin embargo, impulsar una maximización utilitaria desde un punto de vista netamente materialista...quienes practican determinados tipos de virtudes morales y sociales tradicionales... quizá no se hallen en posición tan desventajosa”. Para el autor, las reglas éticas, aquellas que guían la vida del individuo, son alimentadas por la repetición, la tradición y el ejemplo, y son transmitidas de generación en generación como hábitos sociales no razonados. Mas tarde, Fukuyama define el Capital social como el conjunto de normas y valores compartidos que promueven la cooperación social Fukuyama (2003).

El Banco Mundial en su página virtual, indica que el "Capital social es el conjunto de normas y vínculos que permiten la acción social colectiva. Capital social no sólo es la suma de instituciones que apuntalan una sociedad, sino que es el pegamento que las mantiene juntas"2. Existe una gran diversidad de formas desde las cuales se define el capital social, y los conceptos que se le atribuye, así como, la aplicación del mismo, se mueven en un extenso abanico de posibilidades. Ante esto Raúl Atria nos presenta dos dimensiones en las que se puede alinear las distintas formas de abordar la definición del concepto. En la primera, el capital social es entendido como una capacidad específica de movilización de determinados recursos por parte de un grupo. En torno a esta capacidad de movilización, convergen dos elementos sumamente importantes que pueden potenciar tal capacidad: el liderazgo y el empoderamiento. La segunda dimensión se refiere a la disponibilidad de las redes de relaciones sociales; aquí aparecen implicados la noción de asociatividad y el carácter de horizontalidad o verticalidad de las redes, Atria (2003).

Por otro lado, es conveniente distinguir dos tipos de capital social: capital social restringido y capital social ampliado. El primer tipo de capital se presenta al interior de un grupo relativamente pequeño de familiares, amigos o asociados a determinada

2 www.worldbank.org/poverty/scapital. 
organización. Está basado en la confianza particularizada, por tanto, las relaciones de reciprocidad, solidaridad y cooperación son básicamente exclusivas al grupo. En cambio, el capital social ampliado se sustenta en la confianza generalizada, por ende, las relaciones de reciprocidad, solidaridad y cooperación pueden darse con la mayoría de las personas sin importar su condición social, lugar de procedencia, religión, etc. La actitud de que "se puede confiar en la mayoría de la gente" es uno de los elementos cruciales para el desarrollo de las sociedades.

Respecto a la distribución del capital social, la literatura especializada mantiene la tesis que al igual que otros tipos de capital, el capital social está desigualmente distribuido en la sociedad. De modo que dentro de la estructura social, los diferentes grupos sociales tienen una dotación diferenciada de capital social, dada su condición social y la posesión de otros tipos de capital. Pero el control o posesión de otros tipos de capital no es requisito indispensable para acceder al capital social, de lo contrario no sería posible que los pobres, como sostiene Narayan (2006), tengan como principal activo el capital social ya que ellos no poseen acumulaciones mayores de capital físico, financiero, cultural, etc. Esta distribución desigual también se presenta en las organizaciones sociales promovidas por distintas religiones.

Para efectos de la investigación asumimos que el capital social es una configuración de relaciones sociales basadas en actitudes de confianza y comportamientos de solidaridad, reciprocidad y cooperación.

Características del capital social em las doctrinas y creencias religiosas de las Iglesias Católica y Adventista.

Weber (2006), en su obra "Economía y sociedad" expresa que toda acción originada por motivos religiosos es una acción racional. Por consiguiente, el actuar o pensar religioso no puede abstraerse del círculo de las acciones. Para referirnos con mayor claridad a este círculo de las acciones, primero tenemos que comprender la fuente generadora de esas acciones, o como lo denomina Weber, el pensar religioso. Las personas o los grupos humanos en gran medida organizamos nuestra vida a partir de un conjunto de creencias que modelan nuestras acciones. La gente adherida a las religiones cumple esta lógica. Es por ello que primeramente tratamos de entender el sistema de doctrinas y creencias que 
guían el comportamiento de los creyentes. Sin embargo, téngase presente que sólo nos referiremos a aquellas creencias y doctrinas que están en relación al capital social. Esto nos permite restringir el estudio hacia una parte de todo el sistema doctrinario religioso y enfocar el análisis hacia aquellos elementos que refuerzan o limitan el capital social. Sin que ello signifique desvincular los elementos que analizamos del sistema de creencias; pues únicamente pondremos mayor énfasis en el sentido de la vida, la confianza, la solidaridad, reciprocidad y la cooperación.

\subsection{La religión y el sentido de la vida}

La religión proporciona un proyecto de conducta social basado en un orden divino, trascendental y sobrenatural. La religión es -como diría Durkheim- un conjunto de creencias y prácticas que unen a las personas dentro de una comunidad moral. La pertenencia a una "comunidad moral" significa la aceptación de las creencias y doctrinas religiosas que muestran el significado de la vida. Aunque los significados atribuidos a la existencia de las personas puedan variar sustancialmente de una religión a otra, dentro del cristianismo el principio es ser como Cristo, de allí la categoría a las religiones denominadas cristianas. La religión católica y adventista sostienen la existencia de Cristo como Dios hijo. Al preguntarse ¿Por qué estamos vivos? ¿cuál es la razón de la existencia de la humanidad? La respuesta de ambas religiones es similar: Existimos para ser como Cristo, obedecer el mandato divino y alcanzar la salvación. En síntesis: el sentido de la vida para ambas religiones es ser como Cristo, quién obedeció el mandato celestial y es el único camino que conduce a la salvación, y a la vida eterna en el paraíso.

Pero ser como Jesús, es decir, obedecer plenamente el mandato divino, varía según la comprensión de cada religión. Existen varios puntos en los que discrepan las interpretaciones; de estas una está referida al "día del señor" (sábado o domingo), y otra, al modelo de santidad (uno o varios modelos). Veamos las similitudes y diferencias respecto a estos puntos.

\section{a) Modelo de Santidad: ¿uno o varios?}

Los adventistas sostienen que sólo existe un modelo de santidad que es Cristo, puesto que a) sólo a él se le puede adorar y a ningún otro hombre más, b) es el único mediador entre Dios y los hombres, y c) únicamente Jesús como hombre pudo hacer milagros. En 
contraste, la religión católica reconoce oficialmente la santidad de Cristo, proclamándolo como modelo principal de fe y propone a los santos como modelos de imitación. Está de acuerdo en que a) sólo Cristo, y ningún otro hombre más puede ser adorado; a los santos únicamente se les rinde un culto de honra y de profundo respeto denominado veneración. A Cristo se le adora, a los santos se les venera. Esa es la distinción que establece la iglesia católica entre Dios y los santos. b) también admite que Cristo es el único mediador entre Dios y los hombres, pero sostiene que los santos no son un obstáculo para dirigirse directamente a Dios, simplemente que por sus ejemplos de fe son un estímulo para acercarse más a él. c) Los milagros sólo pueden ser realizados por Dios, pero estos pueden ser hechos por intersección de los santos.

Amigo lector, recuerde las distinciones que se están mostrando entre las creencias de ambas religiones. Más adelante nos servirán para explicar el capital social de los creyentes de ambas iglesias.

\section{La confianza social}

La confianza es un concepto que expresa la esperanza firme en algo o en alguien. Tanto la iglesia católica como la adventista predican la confianza entre las personas considerándola como la seguridad firme que se tiene en la gente. Sin embargo, ambas consideran que el ser humano es imperfecto y que puede cometer errores y el único ser perfecto y en el que se puede depositar toda la confianza es Dios; esta reflexión ha conducido a que estas iglesias establezcan una distinción entre el "nosotros" y los "otros", lo cual significa que no todas las personas son dignas de confianza en igual medida debido a que no comparten las mismas creencias y sus comportamientos son distintos.

La distinción entre el "nosotros" y los "otros" se deriva de la importancia diferenciada que ambas religiones atribuyen a la iglesia. La católica sostiene que aceptar a Cristo significa también aceptar su iglesia, la única y la verdadera; a partir de esto se considera que el salirse de la única y verdadera iglesia constituye un pecado. Quienes permanezcan fieles a los designios de la iglesia católica mantienen viva en sus corazones la iglesia que fundó Jesús sobre Pedro. En cambio a diferencia de la católica, la religión adventista sostiene que Cristo es el único que salva, y que la iglesia no posee la facultad para hacerlo. La pertenencia a una u otra iglesia es secundaria ya que lo principal es seguir a Jesús. 
También considera ser la verdadera iglesia, más no la única. El "nosotros" para esta religión está constituido por el grupo remanente de adventistas, los cuales guardan los diez mandamientos y la fe de Jesús, pues son el pequeño pueblo de Dios. Consideran que quienes pertenecen a este grupo remanente son depositarios de confianza; los que aún no forman parte de este grupo son quienes no conocen la verdad, pero pese a esa limitación pueden ser salvos, y además suponen que los "otros" están hambrientos de la palabra de Dios y sedientos del conocimiento de la verdad. De ahí que la misión del remanente es llevar el mensaje de Dios a los que aún no lo conocen.

\section{Sentido de la solidaridad y reciprocidad}

Dos de los elementos que están muy presentes en las doctrinas de ambas religiones se refieren a la solidaridad por un lado, y la reciprocidad por otro, sin embargo ambos elementos están fuertemente entrelazados, por lo que preferimos considerarlos como parte de un mismo aspecto, esto en el sentido de que tanto la solidaridad como la reciprocidad implican una disposición de determinada conducta que en alguna medida llega a concretizarse. La solidaridad está referida al hecho de dar sin necesariamente esperar una retribución, cosa que sucede de modo bastante similar con la reciprocidad con la diferencia que esta si implica la esperanza de una retribución. La similitud principal reside en el incidente de que ambos elementos implican una respuesta premiada por la bondad de las acciones y que esos actos serán recompensados por el favor de Dios en la vida terrenal o en la vida celestial.

La religión católica entiende que la solidaridad es la capacidad de expresar y sentir amor, es decir, respeto, solicitud y responsabilidad con otros seres humanos, no sólo por aquellos cercanos a nosotros, ya sea por vínculo de sangre raza, clase o condición, sino por aquellos que no compartan esos vínculos ni esa cercanía. Por su parte la religión Adventista sostiene que la solidaridad es una entrega del más favorecido hacia el menos favorecido. En el fondo ambas religiones contienen en sus doctrinas la idea de que la solidaridad mantiene el supuesto que no es realizado con el objeto de recibir una retribución a cambio. Es cierto que la solidaridad, en el marco de las religiones que analizamos, tiene un fuerte contenido subjetivo, pero de algún modo se traduce en un suceso que puede reportar una compensación material inesperada. Ambas religiones sostienen la importancia de la solidaridad como elemento de ayuda voluntaria hacia los 
demás sin esperar algo a cambio, pero lo cierto es que la solidaridad reporta beneficios para el solidario. Uno de los beneficios es el respeto. La solidaridad en ambas religiones está orientada hacia la captación de respeto. Por otra parte, la reciprocidad es entendida como la contrapartida de los favores por la prestación de bienes o servicios. Hoy por ti, mañana por mí o viceversa. La religión católica considera que realizar una acción que tenga por intención apoyar a nuestros semejantes es gratificante en el sentido que reporta bienestar espiritual para la persona, pero también se entiende que ese bienestar es de carácter material, puesto que no sólo se realizan apoyos morales y espirituales, sino que el apoyo material, incluso económico, reporta beneficios para los que estén involucrados. Es más: el apoyo material es considerado como un medio que tiende a reforzar los lazos afectivos. En cambio, la religión adventista estima que la reciprocidad entre los miembros es importante porque permite que sus miembros establezcan diversos tipos de ayuda mutua para mejorar sus condiciones de vida. En este punto, ambas religiones coinciden en afirmar que la reciprocidad está orientada a apoyar y recibir apoyo de nuestros semejantes, pero encontramos una diferencia en cuestión de orden, La religión católica considera que se debe de apoyar primero a los semejantes y luego se recibirá la compensación, esto porque doctrinalmente se considera primeramente el servicio a los demás. En contraste, la adventista sostiene que primero es uno mismo el que tiene que desarrollarse como persona, y en esa medida podrá apoyar a los demás. Esto porque la religión adventista doctrinalmente tiene muy presente que el hombre es imperfecto y en su camino a la perfección obtendrá las capacidades y los medios para poderlos compartir; pues uno no puede dar lo que no tiene. Si no puedes amarte a ti mismo cómo puedes amar a los demás. Pues el cambio empieza por uno mismo y luego podrás ayudar a los demás.

\subsection{La cooperación como elemento integrador}

Otro elemento que hace posible hablar de capital social es el referido a la cooperación, y no es para nada ajeno que se presente en las religiones. Podemos afirmar que la cooperación es un elemento integrador al interior de ambas iglesias, pues representa en sí el trabajo que realizan las personas dentro de una comunidad en beneficio del colectivo, causando esto a la vez el apego y mayor unificación de los integrantes de los grupos religiosos. En las doctrinas de ambas religiones la cooperación se presenta como el vínculo que mantiene unido al colectivo. La adventista sostiene que la cooperación al 
interior del grupo tiende a reforzar los lazos de afectividad, llegando a considerarse entre ellos como hermanos, ello implica asumir responsabilidades compartidas, aquí la persona constituye el elemento fundamental para lograr la unificación del grupo, La contribución de cada una de las personas en diversas actividades conjuntas es considerada el sostén de la iglesia. Al igual que la adventista, la religión católica sostiene que la cooperación entre los creyentes tiende a la unificación del grupo, sin embargo, atribuye mayor importancia al colectivo que al individuo, puesto que sostiene que la iglesia es más que la suma de sus fieles.

\section{RESULTADOS Y DISCUSIÓN}

\subsection{CAPITAL SOCIAL ENTRE LOS CREYENTES DE LA MISMA IGLESIA}

Se considera importante hacer la distinción entre la confianza al interior del grupo, y de este al exterior, ya que existen diferencias. En el siguiente capítulo veremos como se proyecta el capital social de los feligreses de ambas iglesias hacia el exterior de las mismas. Antes veamos como se presenta al interior de las iglesias católica y adventista.

\subsubsection{Confianza}

Del total de encuestados de la iglesia católica y adventista el $86.6 \%$ y el $67 \%$ respectivamente confían siempre y casi siempre en los miembros de su misma religión. Las razones por las que confían son las siguientes: porque pertenecen a mi misma religión (católicos $18.7 \%$ y adventistas $6.8 \%$ ), porque son dignos de confianza (14.9\% y $1.9 \%$ respectivamente). Por otro lado, existe un reducido margen de católicos que confían poco en los miembros de su iglesia, $13.4 \%$, a diferencia de los adventistas que alcanzan el $30.1 \%$, las razones en ambas iglesias son: las personas pueden fallarte alguna vez (católicos 14.9\% y adventistas 25.2\%), porque no profesan plenamente la religión (5.2\% y 0\% respectivamente), y un pequeño margen menciona no confiar en las personas de su iglesia porque aún no las conocen mucho (3.7\% y 9.7\% correspondientemente). Existe un $2.9 \%$ de adventistas que mencionan que nunca confían en los miembros de su iglesia, en tanto que en la católica el porcentaje de $0 \%$.

A partir de lo expuesto anteriormente, se deduce que relativamente los adventistas confían menos que los católicos en los creyentes de su misma religión. ¿Por qué? La explicación va por el lado de las creencias. Algunos adventistas basan su desconfianza en un texto bíblico que dice: "maldito el varón que confía en los hombres". De ahí entienden que no 
se debe confiar en los hombres más que en Dios. Además que consideran que la relación más profunda e intima con Dios se da en forma directa, sin intermediación alguna . En cambio, ¿por qué los católicos confían más entre ellos? Otra vez orientemos la explicación hacia lo doctrinal: los católicos creen en la intermediación entre Dios y los hombres, sobre esta base se entretejen relaciones de confianza con quienes consideran que representan la autoridad divina en el mundo terrenal, es decir, muestran confianza en los párrocos, líderes, y demás autoridades religiosas. Hecho que no se da entre los adventistas.

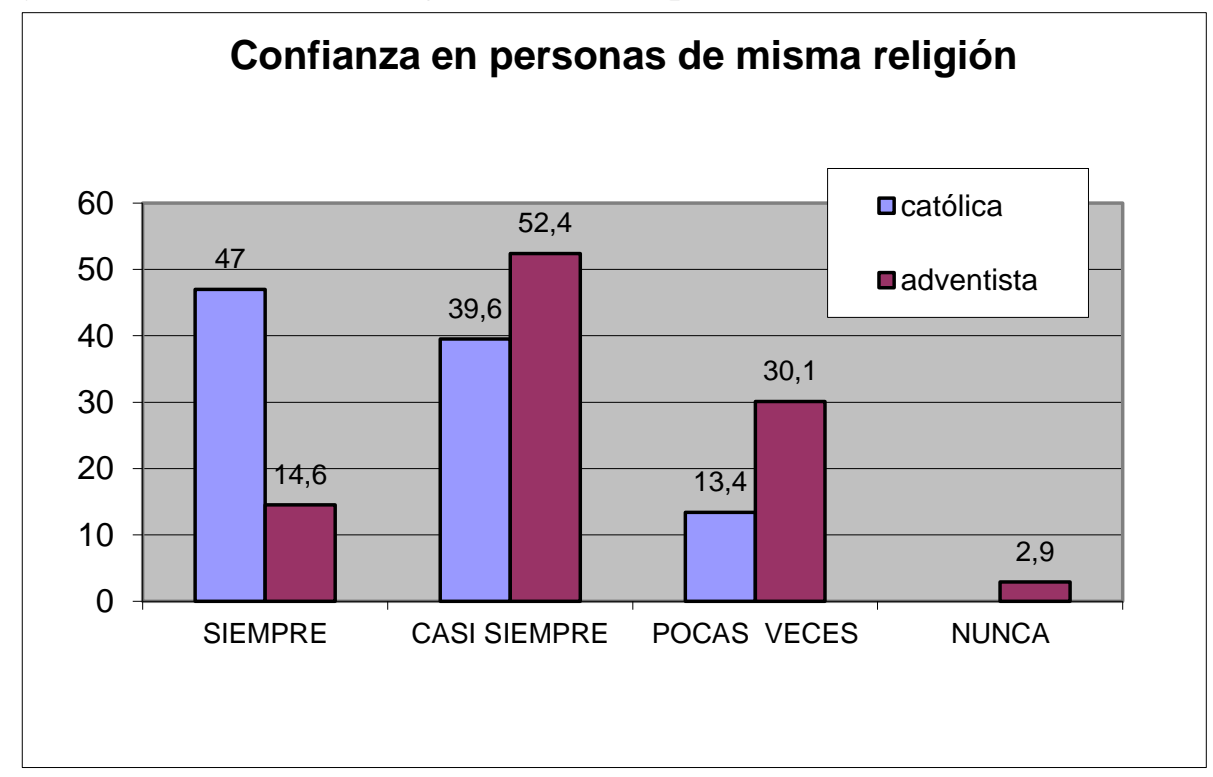

Fuente: elaboración propia.

\subsubsection{Solidaridad y reciprocidad: Formas de Ayuda}

Encontramos gran potencial de parte de ambas iglesias en cuanto a su disposición para ayudarse entre ellos mismos. El 90.3\% de católicos y el $97.1 \%$ de adventistas declara su actitud de ayuda hacia las personas de su misma religión. Una actitud es una predisposición anímica para la realización de acciones, sustentada en creencias, valores, doctrinas, que pesan sobre la persona. Esta actitud se refuerza en las religiones cristianas debido a que las doctrinas católica y adventista orientan la acción de las personas hacia la ayuda al prójimo, considerando básicamente que "amar es compartir”. Pero ¿cómo se manifiestan estas actitudes? Hemos encontrado que se expresan básicamente en dos formas: a) material y económicamente, y b) emocional y moralmente. 


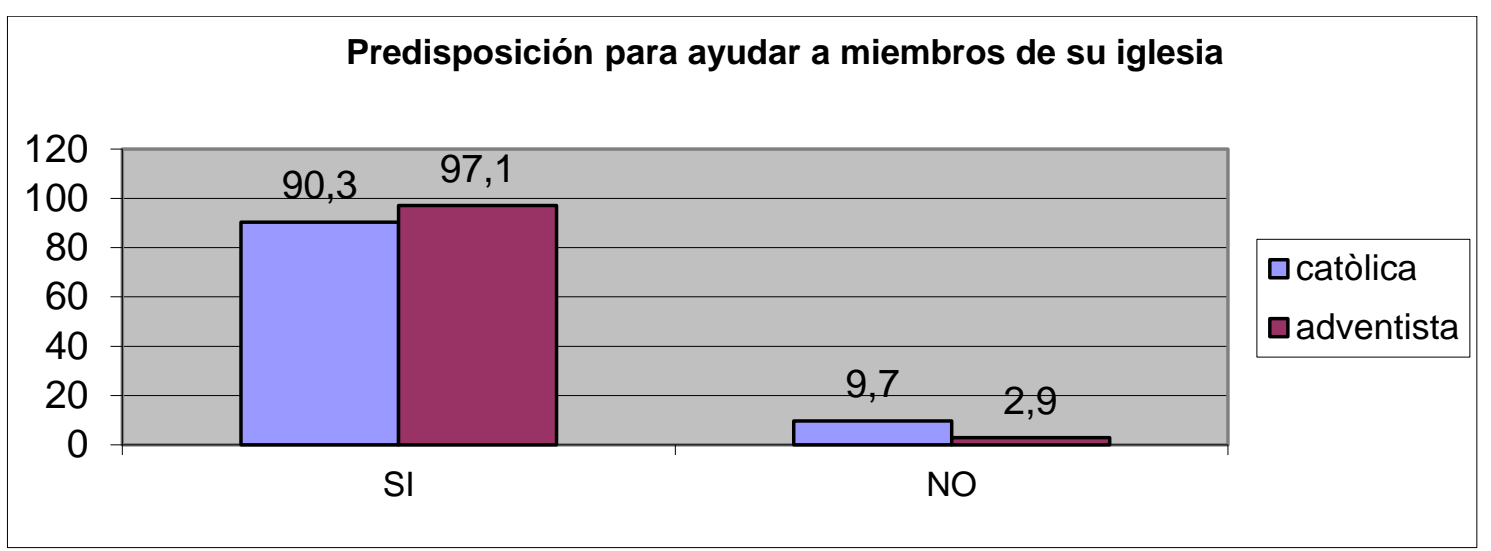

Fuente: elaboración propia.

Respecto a las formas de ayuda que realizan los católicos y adventistas entre ellos mismos, no hallamos diferencias significativas; tal es así que el 19.8\% de católicos y el 19.2\% de adventistas brindan a sus "hermanos" apoyo material y económico, es decir, prestan dinero, materiales de estudio, prendas de vestir y accesorios, entre otros. El 55.6\% de católicos y el 53.8\% de adventistas ofrece servicios de apoyo emocional y moral, dando consejos, motivándolos y guiándolos en la comprensión de la Biblia. Por otro lado, el $24.7 \%$ de católicos y el $26.9 \%$ de adventistas combinan ambas formas de ayuda. Cabe resaltar que la forma de ayuda más común entre los creyentes de una misma religión es la emocional y moral. Esto se entendería por la misma lógica de las iglesias: están más cerca de lo intangible que lo material, es decir, se interesan más por el desarrollo espiritual y moral de sus feligreses.

En el cuadro anterior apreciamos que en ambas religiones la confianza entre los creyentes es diferenciada. El $57.5 \%$ de los católicos aseguran que confían en la mayoría de las personas que pertenecen a su religión, mientras que sólo el 35.9\% de adventistas coinciden con esta opinión. Los que significa que de manera general los católicos confían más en sus "hermanos" de religión que los adventistas. Si nos fijamos en el dato siguiente: más del $61.2 \%$ de los adventistas menciona que confía sólo en algunos miembros de su misma religión, este porcentaje es bastante alto si lo comparamos con los católicos que declaran lo mismo(38.8\%). Finalmente los que manifiestan no confiar en ninguno de sus "hermanos" son, por un lado, el 3.7\% de católicos, y por el otro, $2.9 \%$, adventistas. 
La mayoría de los católicos $(57.5 \%)$ creen que la mayoría de las personas de su misma religión le pueden ayudar, mientras que la mayoría de los adventistas (61\%) cree que sólo algunas personas pertenecientes a su religión podrían ayudarlo.

Cuando los Miembros de mi Grupo me Hacen un Favor:

La forma que utilizamos para medir el grado de reciprocidad al interior del grupo religioso fue a través del uso de supuestos como por ejemplo en el caso de recibir ayuda de algún miembro de su religión, qué acción u operación, realizaría la persona beneficiaria como forma de retribución, la respuesta común a esta pregunta es la correspondencia del mismo modo, de los jóvenes católicos el 59.7\% dio esa respuesta y de los adventistas sólo lo hizo el 35\% notándose una diferencia del mas del 20\% entre ambos, ya que los católicos tienden a priorizar mas el hecho de la correspondencia, ya que se genera una obligación, de correspondencia, ello tiende a fortalecer los lazos de confianza frente a la otra persona. Así lo considera un 30\% de los católicos, mientras que en los adventistas es un 36\%. El hecho de hacer o ser beneficiario de favores por parte de los jóvenes de ambas religiones tiende en gran medida a reforzar las relaciones de confianza y crean un sentido de correspondencia frente al otro.

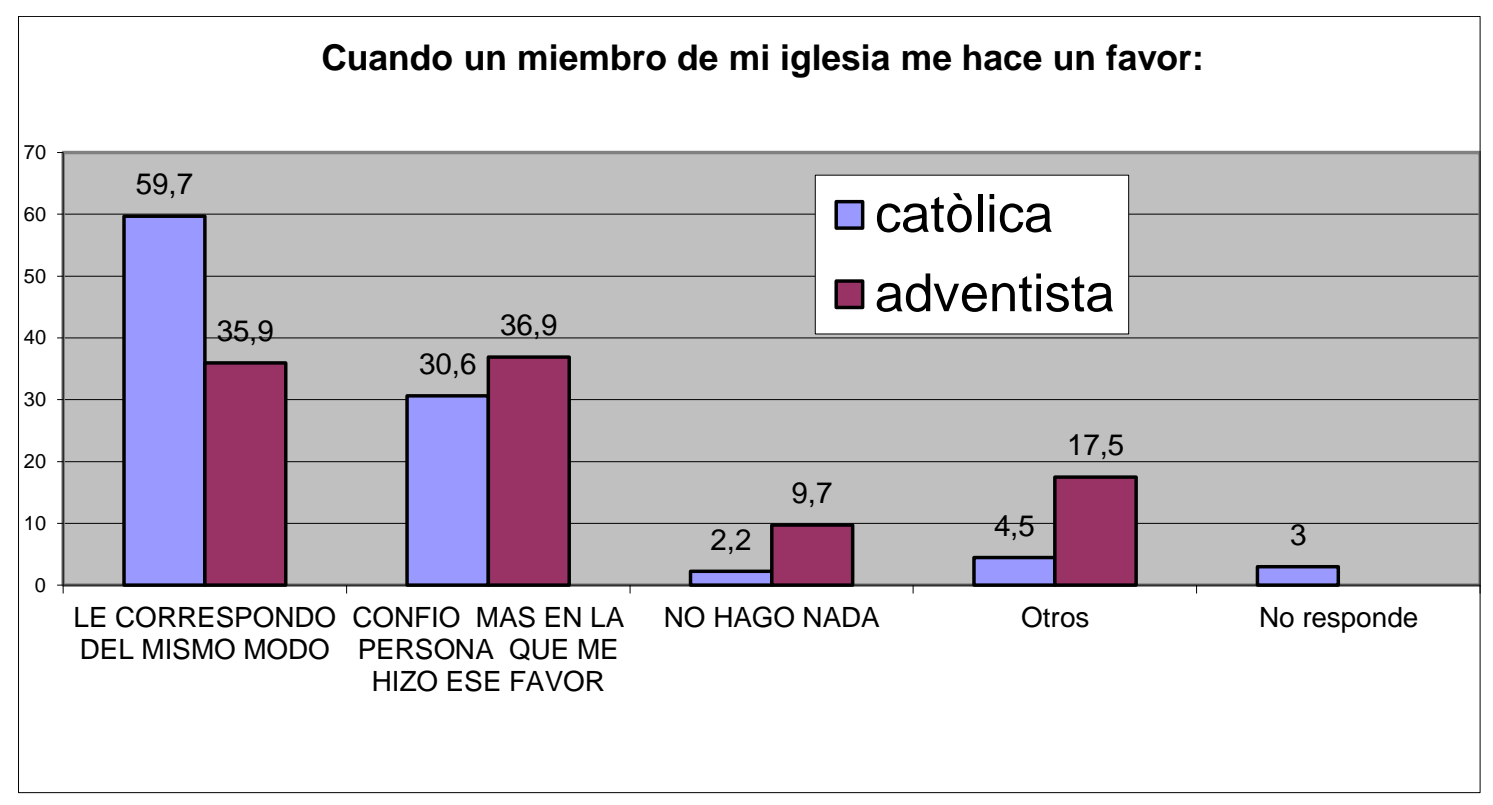

Fuente: elaboración propia. 
Para medir el nivel de reciprocidad que se presenta al interior de las iglesias utilizamos alternativas múltiples a una interrogante implícita: “Cuál es su reacción cuando un miembro de su iglesia le hace un favor? También aquí encontramos algunas diferencias en las respuestas. Son más los católicos (59.7\%) que los adventistas (35.9\%) que manifiestan corresponder del mimo modo al favor que le hacen los miembros de su iglesia. Por otro lado, el $30.6 \%$ de católicos y $36.9 \%$ de adventistas aseguran confiar más en la persona que les hizo algún favor.

\subsubsection{Cooperación}

La cooperación entre los creyentes de una misma religión es importante para mantener cohesionado un grupo religioso, la cooperación puede presentarse de formas distintas. Una forma que aquí presentamos es el trabajo conjunto entre las personas para el beneficio del grupo al cual pertenecen. Los católicos tienden a participar conjuntamente con miembros de su misma religión en mayor medida que los adventistas, tal como se muestra en el cuadro siguiente.

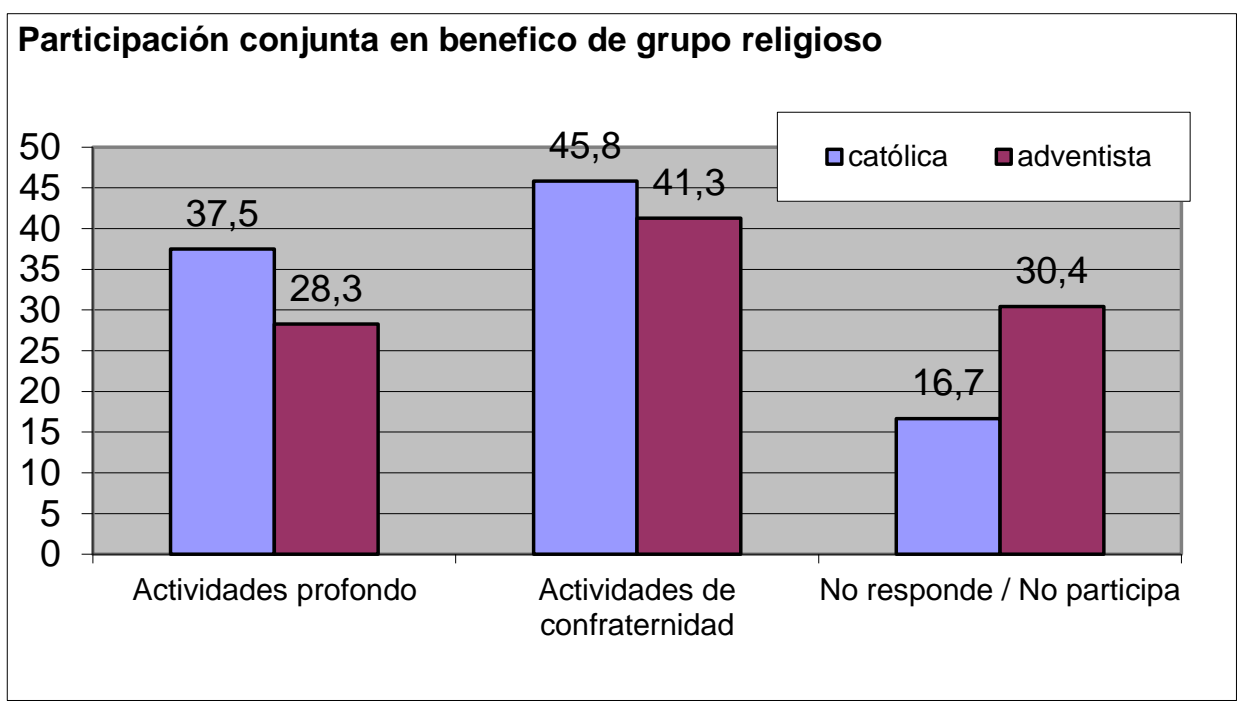

Fuente: elaboración propia.

El 71.6\% de católicos ha participado conjuntamente con personas de su iglesia para el benéfico de su grupo, mientras que únicamente el $44.7 \%$ de adventistas declara haber hecho lo mismo. Esto refleja de algún modo una mayor cooperación entre los católicos que entre los adventistas. Ello puede también explicarse a partir de las normas de conducta que imparten cada una de las religiones. 
Las actividades más atractivas para los creyentes y en las que más participan son en las de confraternidad, cerca de la mitad de los católicos (45.8\%) participan básicamente en este tipo de actividades, en cambio los adventistas que participan preponderadamente en estas actividades ascienden al $41.3 \%$ de los mismos. Las actividades de confraternidad son las preferidas por católicos y adventistas, ambas iglesias presentan mayor apertura hacia la confraternidad. Es en este tipo de actividades que se renuevan lazos de confianza y se reafirma el sentido de pertenencia, en segundo lugar se ubican las actividades de profondo: son preferidas por el $37.5 \%$ de católicos y el $28.3 \%$ de adventistas. Una vez más encontramos que los adventistas ocupan el primer lugar de los porcentajes que se ubican en No responde / No participa con un 30.4\%, mientras que los católicos alcanzan la cifra porcentual de $16.7 \%$. es decir, los adventistas cooperan en menor medida que los católicos en actividades como las mencionadas,

\subsubsection{Normas de conducta}

Encontramos que mientras el $64.9 \%$ de los creyentes católicos consideran que la principal sanción impuesta para mantener la estabilidad y cohesión de los grupos religiosos es la "llamada de atención", en el caso de los adventistas el 53.4\% consideran que "no pasa nada". Esta diferencia sobre la percepción de las sanciones contiene principios doctrinarios. Los católicos aceptan la intermediación entre Dios y los hombres, esta intermediación es representada por el sacerdote a nivel parroquial y por el líder a nivel de grupo; es por ello que las "llamadas de atención" de un líder hacia los demás miembros son legítima, no por la persona de la cual emana esa sanción, sino por lo que representa. En contraste, los adventistas consideran que no existe mediación entre Cristo y los hombres. Las acciones de las personas sólo pueden ser juzgadas por un ser divino, lo que significa que uno está sujeto a su conciencia y ante el que tendrá que responder por todos sus actos es Dios. Esto explica el por qué la mayoría responde que para mantener cohesionado al grupo no es necesario la sanción, pues simplemente "no pasa nada". Aquí la sanción es de carácter más subjetivo, más personal. 


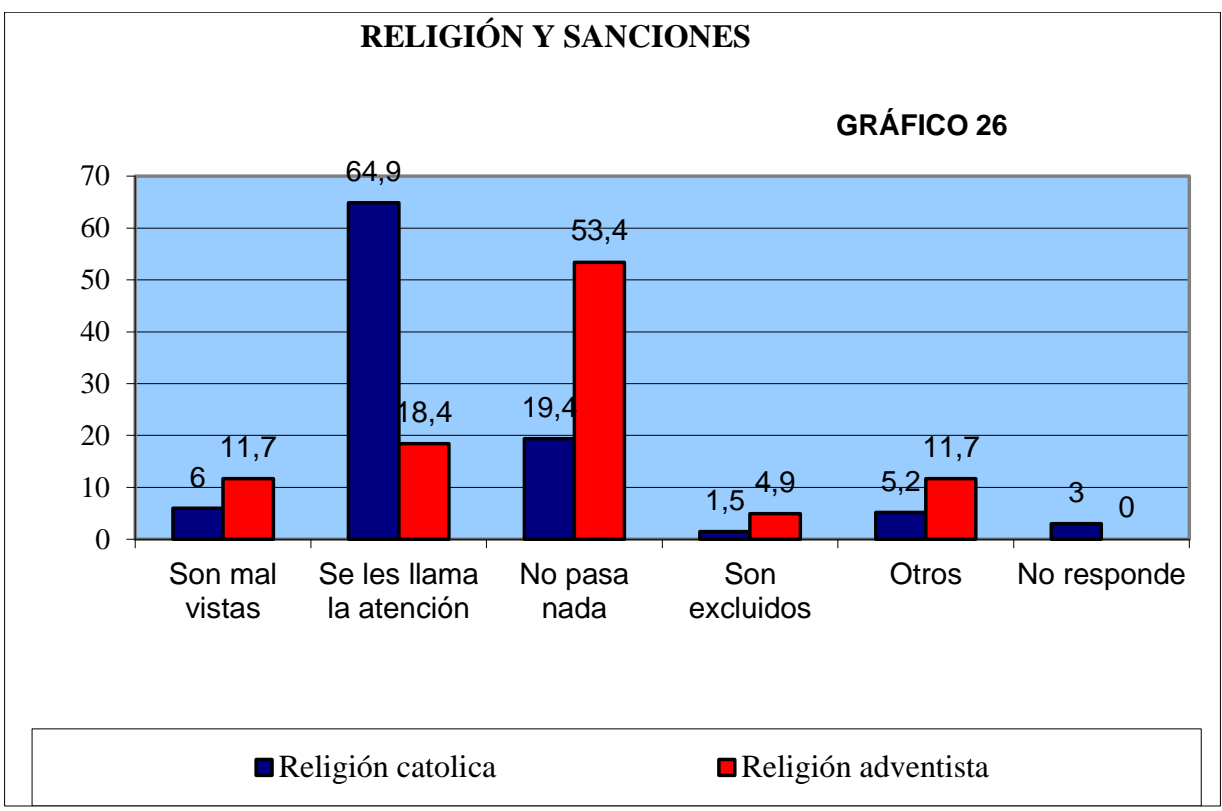

Fuente: elaboración propia.

Por lo tanto, las formas de control en ambas iglesias son diferenciadas, una presenta mayor control social (Católica) y la otra, mayor control personal, subjetivo, emocional (Adventista).

\subsection{CAPITAL SOCIAL HACIA EL EXTERIOR DE LA IGLESIA}

En el capítulo anterior hemos ido viendo las diferencias que se han ido encontrando respecto al capital social que se desarrolla al interior de las iglesias. Para decirlo de otro modo. La confianza, la solidaridad, reciprocidad y cooperación se establecen de modos diferentes entre las dos iglesias comparadas. Aunque las diferencias algunas veces son poco significativas, en la mayoría de los casos presentados hemos encontrado que son divergentes. Ahora veamos como el capital social de los creyentes de ambas religiones se proyecta al exterior de las iglesias. Primeramente hablaremos de la confianza, luego de la solidaridad y reciprocidad, para después pasar a la cooperación. Entre los elementos mencionados, que son tema del presente estudio, incluimos la respuesta a otras interrogantes: ¿Por quienes están conformados los círculos de amistades más cercanas de los creyentes de ambas religiones? ¿Pertenecen a alguna otra organización social a parte de las que hay en sus iglesias? Estas preguntas también nos orientan al entendimiento del capital social de los creyentes activos. Iremos desarrollando cada uno de estos temas. Empecemos con la confianza. 


\subsubsection{Confianza generalizada}

La confianza generalizada sustenta al capital social ampliado. Confiar en la mayoría de las personas por encima de las distinciones de clase, raza, género, procedencia, le hace bien a cualquier sociedad. Uno de los elementos característicos de las religiones es la confianza firme en una vida digna para todos, sin discriminaciones ni distinciones de clase, un nuevo mundo en el que las personas podrán desarrollarse libremente. A partir de esta esperanza en un nuevo mundo, las iglesias desarrollan actitudes particulares que están referidas a como alcanzar a formar parte de ese nuevo mundo. Ahora, la inquietud que se nos presenta es si las religiones están o no fortaleciendo el capital social ampliado como instancia necesaria para lograr ingresar al nuevo mundo y formar parte de él por siempre.

En términos generales tanto los creyentes de la iglesia católica como de la adventista presentan actitudes que expresan su poca confianza en las demás personas. Muy por encima de la mitad de los creyentes de ambas iglesias consideran que primero se debe de conocer a las personas antes de confiar en ellas. Pero quienes expresan en mayor medida esto son los adventistas (72.8\%) en comparación a los católicos (69.4\%). Sin embargo, las personas que conciben que se puede confiar en la mayoría de las personas sin importar su religión son una proporción bastante pequeña en relación con los que mencionan que antes es necesario primero conocerlas (católicos $26.1 \%$, adventistas $27.2 \%$ ).

\subsubsection{Conformación del círculo de amistades más cercanas}

Los adolescentes y jóvenes de la religión católica en su mayoría (51.5\%) tienden a conformar su círculo de amistades con personas de su misma religión. En cambio, los de la religión adventista tienen círculos de amistades integrados por personas de su misma religión y de otras. Pero ¿cómo es posible que los adventistas tengan también dentro de su círculo de amistades a personas de otras religiones si venimos diciendo que son ellos quienes confían menos en la mayoría de las personas a comparación de los católicos? Aunque el último dato pueda expresar una aparente contradicción, el fondo no es más que eso: apariencia. En una sociedad como la nuestra que está conformada predominantemente por fieles católicos, es razonable que quienes pertenezcan a otras religiones también tengan dentro de su círculo de amistades cercanas a miembros de otras religiones y básicamente 
estos miembros serían católicos. Esta reflexión explica además el por qué la mayoría de los católicos tienen dentro de sus círculos de amigos más cercanos a más católicos.

\subsubsection{Solidaridad y reciprocidad}

La disposición de los creyentes por ayudar a las personas es, en términos relativos, bastante alta. Respecto a este mismo punto, el $90.3 \%$ de creyentes católicos tienen un sí como respuesta, es decir, sí están dispuestos a ayudar a las personas que lo necesiten y a colaborar con ellas en cuanto puedan. Una cifra similar es la que se presenta entre los adventistas (87.4\%), con una ligera diferencia (de $2.9 \%)$.

De modo general podemos decir que son más los católicos (47\%) que los adventistas (34\%) quienes realizan favores a las demás personas. Pero la mayoría de los creyentes de ambas religiones están ubicados en el segmento de No responde / No hizo favores ( 53\% católicos y $66 \%$ adventistas). Los favores que más se hacen son de carácter moral y espiritual (23.1\% católicos y $24.3 \%$ adventistas), entendiendo por ellos a los servicios de consejería, reanimación, enseñanza de la palabra divina.

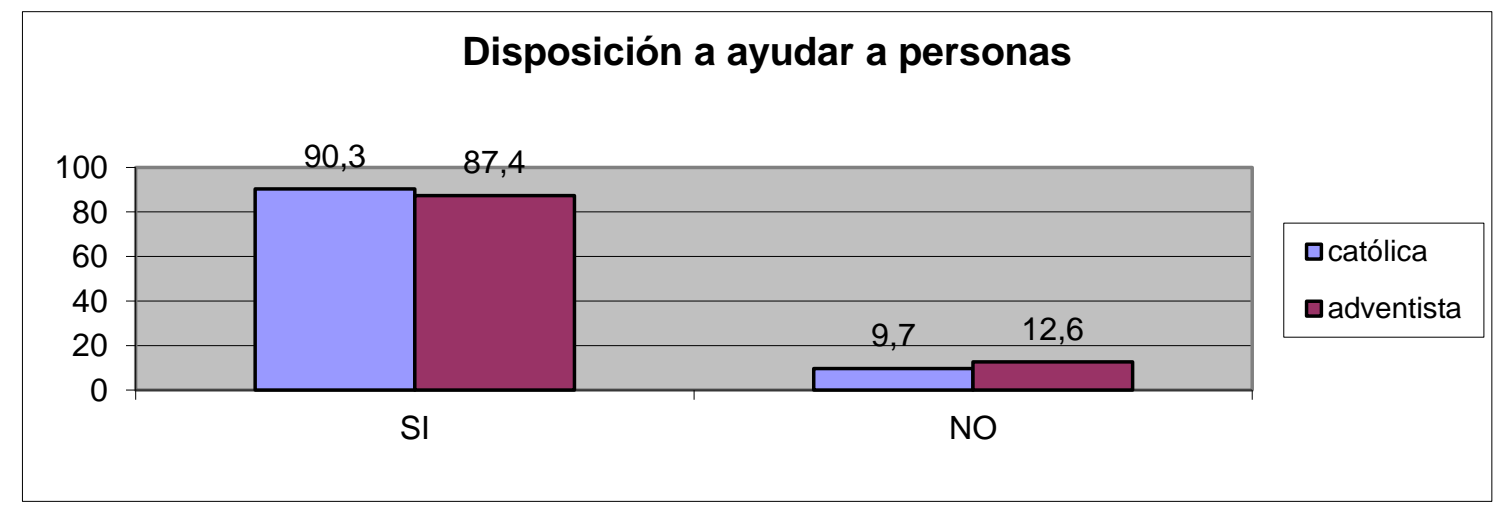

Fuente: elaboración propia.

Adventistas y católicos coinciden en considerar que lo importante es ayudar a los demás sin esperar una retribución. La mayoría de los católicos (72.4\%) y adventistas (61.2\%) están muy de acuerdo con tal afirmación.

Planteamos una otra afirmación a los creyentes para tratar de confirmar la disposición hacia la solidaridad y reciprocidad. La afirmación que se plantea a los miembros de ambas iglesias fue "no vale la pena hacer favores a las personas porque siempre pagan mal ". Si en una sola cifra incluimos a quienes están en desacuerdo y muy en desacuerdo con la 
afirmación anterior, notamos que la gran mayoría de los creyentes católicos (91\%) y adventistas (71.8\%) rechazan la afirmación. Nótese también que son menos los adventistas en comparación con los católicos los que rebaten tal afirmación.

\subsubsection{Cooperación}

Se preguntó a los encuestados si en el último año trabajaron conjuntamente con personas de su distrito para el benéfico de su comunidad. La respuesta de los creyentes católicos (72.4\%) y adventistas ( 90.3\%) es predominante negativa. Aunque cabe destacar una diferencia: son más los creyentes católicos que cooperaron con sus vecinos por el benéfico de su localidad o comunidad.

\subsubsection{Participación en organizaciones}

Al preguntar a los creyentes de ambas religiones sobre su participación en organizaciones externas a sus iglesias, encontramos que la gran mayoría no pertenece a ninguna asociación o grupo. Un reducido margen de creyentes que pertenecen a organizaciones externas a su iglesia están distribuidos en organizaciones políticas (2.2\% de católicos), organizaciones culturales y educativas (16.4\% de católicos) y organizaciones comunales $(1.3 \%$ de católicos). Como se habrá dado cuenta, no se registra ningún adventista en ninguna de las organizaciones mencionadas. El 100\% de adventistas se ubica en el segmento de los que No participan / No responden.

\section{CONSIDERACIONES FINALES}

- El sentido de la vida tanto para religión católica como para la adventista es ser como Cristo. Pero ser como Jesús, es decir, obedecer plenamente el mandato divino, varía según la comprensión de cada religión. Existen varios puntos en los que discrepan las interpretaciones; de estas una está referida al "día del señor” (¿sábado o domingo?), y otra, al modelo de santidad (¿uno o varios modelos?). Los adventistas creen que el "Día del Señor" es el sábado y sólo existe un sólo modelo de imitación que es Cristo. En cambio para los católicos el "Día del Señor” es el domingo y creen en los santos como modelos de fe pero el principal es Cristo.

- Tanto la iglesia católica como la adventista predican la confianza entre las personas considerándola como la seguridad firme que se tiene en la gente. Ambas mantienen 
la idea que hay personas en las que se puede confiar más que en otras. La explicación a esto se deriva de la concepción que tienen sobre la iglesia. Para la religión católica su iglesia es única y verdadera, por tanto quienes pertenezcan ahí se encuentran en la única iglesia fundada por Cristo; en cambio, para los adventistas su iglesia no es la única, pero sí la verdadera. Consideran que la iglesia es secundaria porque Cristo es el único que salva, más no la iglesia. Por tanto, si bien confían en las personas aunque más en los de su iglesia, en el único que se puede plenamente confiar es en Cristo.

- La religión católica entiende que la solidaridad es la capacidad de expresar y sentir amor, es decir, respeto, solicitud y responsabilidad con los demás seres humanos. Por su parte la religión Adventista sostiene que la solidaridad es una entrega del más favorecido hacia el menos favorecido. La solidaridad en ambas religiones está orientada hacia la captación de respeto. Ambas religiones coinciden en afirmar que la reciprocidad está orientada a apoyar y recibir apoyo de nuestros semejantes, pero encontramos una diferencia en cuestión de orden, La religión católica considera que se debe de apoyar primero a los semejantes y luego se recibirá la compensación, esto porque doctrinalmente se considera primeramente el servicio a los demás. En contraste, la adventista sostiene que primero es uno mismo el que tiene que desarrollarse como persona, y en esa medida podrá apoyar a los demás. Esto porque doctrinalmente tiene muy presente que el hombre es imperfecto y en su camino a la perfección obtendrá las capacidades y los medios para poderlos compartir (pues si no puedes amarte a ti mismo cómo puedes amar a los demás).

- En las doctrinas de ambas religiones la cooperación se presenta como el vínculo que mantiene unido al colectivo. Al igual que la adventista, la religión católica sostiene que la cooperación entre los creyentes tiende a la unificación del grupo, sin embargo, asigna mayor importancia al colectivo que al individuo, puesto que sostiene que la iglesia es más que la suma de sus fieles. Y la adventista atribuye mayor importancia al individuo porque considera que individuo constituye la parte fundamental en toda relación social como puede implicar la cooperación.

- Dentro de las iglesias se institucionaliza un conjunto de normas de conducta sustentadas básicamente en sus doctrinas y legitimas por el conjunto de sus feligreses. Mientras las sanciones como los incentivos en la iglesia católica son básicamente de carácter social, en la adventista son preponderantemente de carácter individual. 
- Gran parte de los católicos (71.6\%) participan conjuntamente con personas de su iglesia para el benéfico de su grupo, mientras que es menor la cantidad de adventistas (44.7\%) que hacen lo mismo. Esto refleja de algún modo una mayor cooperación entre los católicos que entre los adventistas.

- Las formas de control en ambas iglesias son diferenciadas, una presenta mayor control social (Católica) y la otra, mayor control personal, subjetivo, emocional (Adventista).Mientras la mayoría de los creyentes católicos (64.9\%) consideran que la principal sanción impuesta para mantener la estabilidad y cohesión de los grupos religiosos es la "llamada de atención", la mayoría de los adventistas ( 53.4\%) consideran que "no pasa nada". Esta diferencia sobre la percepción de las sanciones a partir de principios doctrinarios. Los católicos aceptan la intermediación entre Dios y los hombres, esta intermediación es representada por el sacerdote a nivel parroquial y por el líder a nivel de grupo; es por ello que las "llamadas de atención” de un líder hacia los demás miembros son legítimas, no por la persona de la cual emana esa sanción, sino por lo que representa. En contraste, los adventistas consideran que no existe mediación entre Cristo y los hombres. Las acciones de las personas sólo pueden ser juzgadas por un ser divino, lo cual significa que uno está sujeto a su conciencia y ante el que tendrá que responder por todos sus actos es ante Dios. Esto explica el por qué la mayoría responde que para mantener cohesionado al grupo no es necesario la sanción, pues simplemente "no pasa nada". Aquí la sanción es de carácter más subjetivo, más personal.

- Muy por encima de la mitad de los creyentes de ambas iglesias consideran que primero se debe de conocer a las personas antes de confiar en ellas. Pero quienes expresan en mayor medida esto son los adventistas (72.8\%) en comparación a los católicos $(69.4 \%)$.

- Los adolescentes y jóvenes de la religión católica en su mayoría (51.5\%) tienden a conformar su círculo de amistades con personas de su misma religión. En cambio, los de la religión adventista tienen círculos de amistades integrados por personas de su misma religión y de otras. En una sociedad como la nuestra que está conformada predominantemente por fieles católicos, es razonable que quienes pertenezcan a otras religiones también tengan dentro de su círculo de amistades cercanas a miembros de otras religiones y básicamente estos miembros serían católicos. Esta reflexión explica 
además el por qué la mayoría de los católicos tienen dentro de sus círculos de amigos más cercanos a más católicos. Además si consideramos que ambas religiones son cristianas, la aceptación entre uno y otro es más factible.

- La gran mayoría de católicos como adventistas no pertenecen a ninguna asociación o grupo externo a las iglesias. Un reducido margen de creyentes que pertenece a organizaciones externas a su iglesia están distribuidos en organizaciones políticas (2.2\% de católicos), organizaciones culturales y educativas (16.4\% de católicos) y organizaciones comunales (1.3\% de católicos). No se ha registrado a ningún adventista que forma parte de alguna organización externa a su iglesia.

- Las religiones generan capital social de manera diferenciada en los creyentes activos. Hemos encontrado que al interior de la las iglesias el capital social es más activo entre los creyentes de una misma religión y que el capital social se proyecta de forma menos intensa hacia el exterior de las iglesias, en otros términos, las actitudes de confianza y las relaciones de solidaridad, reciprocidad y cooperación son más intensas entre los creyentes de una misma religión que con las personas en general. De modo que se establece una diferenciación respecto al tipo de capital, siendo relativamente restringido.

Esperamos que nuestro aporte ayude a responder la pregunta inicial con la que iniciamos la presentación del presente trabajo: ¿Cómo hacer para enrumbar un proceso de desarrollo sostenido que garantice una vida digna para todos? Un impulso para enrumbar el proceso de desarrollo está en fuerza de la religión y la espiritualidad de las personas. Lo que mиeve y arrastra al mundo no son las máquinas, sino las ideas (Víctor Hugo). La esperanza en el futuro tiene fuerza movilizadota en el presente. 


\section{LISTA DE REFERENCIAS}

Aliaga, L. (2003). ¿Qué haría yo si no tuviera capital?. En: Debates en sociología $\mathrm{N}^{\circ} 28$. Lima: PUCE

Ballón, H. (2004). Análisis sociojurídico de la religión en Arequipa. Arequipa: UNSA.

Bastian, J. (1994) Protestantismo y modernidad latinoamericana. México: FCE.

Foucalt, M. (2003) Microfísica del poder. Barcelona: Taurus

Gelles, R. (1996). Introducción a la sociología. México

Gutierrez, G. (1990) Teología y liberación. Lima: CEP

Irazabal, D. (2003) Un Jesús jovial. Lima: Paulinas

Irazabal, D. (1993) Rito y pensar cristiano. Lima: CEP

Izquierdo, C. (s/f) La autoestima. Bogotá: Paulinas

Jordán M. (2000) Sepa Defender su Fe. Arequipa: Don Bosco.

Light, D. (1991). Sociología. México

Marx, C. (1984). Manifiesto del Partido comunista

Montes, A. y Catacora J. (2005) El papel de las redes sociales en la reproducción y desarrollo de la microempresa rural no agrícola: la experiencia de Arequipa y Moquegua. Arequipa: Ceder

Ortmann, D. (2010) Ciencias de la religión en el Perú.

Portal Católico. www.encuentra.com

Restrepo, A. (2004) Ética y valores, 1 y 2. Bogotá: Paulinas

Schumpeter, J. (s/f) Capitalismo, socialismo y democracia

Varios (1992) La nueva evangelización. Lima: CEP 
Veintisiete doctrina de la iglesia adventista

Weber, M.(2004) La Ética protestante y el espíritu del capitalismo

Weber, M.(2006) Economía y sociedad 